\title{
ABO-Rhesus Blood Group Distribution among Peri-Partum Car- diomyopathy Patients: A Multi-Center Study in Sokoto, Nigeria
}

\begin{abstract}
Hayatu Umar, MBBS, MSc, FWACP ${ }^{1 *}$, Simeon Alabi Isezuo, MBBS, MPH, FMCP, FESC ${ }^{1}$, Muawiyya Zagga Usman, MBBS, FMCP1, Adeshina A Yusuf, MBBS ${ }^{1}$, Bello Tambuwal Umar, MBBS, MMED (Int. Med) ${ }^{2}$, Femi Akindotun Akintomide, MBBS, FMCP ${ }^{1}$, Abdulaziz Aminu, MBBS ${ }^{1}$, Aminu Sakajiki Muhammad, MBBS, MSC, FMCP1, Abubakar Sadiq Maiyaki, MBBS, FWACP1, Hamidu Muhammad Liman, MBBS, FMCP1, Isah Omokhudu Oborien, MBBS, FMCP1, Musa Baba Muhammad, MBBS, FWACP3, Abdulmumini Yakubu, MBBS, FWACP1, Samaila Bello, MBBS ${ }^{4}$, Usman Muhammad Waziri, MBBS, FMCP ${ }^{5}$, Nicholas Oluwamayowa Omoniyi, MBBS ${ }^{1}$, Musa Tambuwal Umar, MBBS, FMCP1 and Adamu Jibril Bamaiyi, MBBS, MSc, PhD ${ }^{6}$
\end{abstract}

\author{
${ }^{1}$ Department of Internal Medicine, Usmanu Danfodiyo University, Nigeria \\ ${ }^{2}$ Department of Medicine, Specialist Hospital Sokoto, Nigeria \\ ${ }^{3}$ Department of Medicine, Federal Medical Centre, Nguru, Yobe state, Nigeria \\ ${ }^{4}$ Department of Radiology, Usmanu Danfodiyo University Teaching Hospital, Nigeria \\ ${ }^{5}$ Department of Pediatrics, Usmanu Danfodiyo University, Nigeria \\ ${ }^{6}$ Department of Physiology, Usmanu Danfodiyo University, Nigeria
}

*Corresponding author: Hayatu Umar, MBBS, MSC, FWACP, Department of Internal Medicine, Usmanu Danfodiyo University Teaching Hospital, Sokoto, Nigeria, Tel: +2348095100566

\begin{abstract}
Background: Cardiovascular disease is a major cause of death among women of child bearing age in Northern Nigeria. As much as $60 \%$ of Peripartum Cardiomyopathy (PPCM) was reported among women with heart failures in a tertiary health institution in Sokoto, Northwestern Nigeria and was responsible for about $34 \%$ of deaths in peripartum women in South Africa. The Millennium and Sustainable Development Goals (MDG \& SDG) 2000 to 2015 and 2015 to 2030, respectively have it as their cardinal quests, to reduce maternal deaths ratio by three quarter by the year 2030. Studies have identified the risk factors of cardiovascular diseases among women in their reproductive age and a study had observed that cardiovascular diseases may be partly explained by blood group polymorphism, but none to our knowledge has considered the possible association of the various sub-classes of $\mathrm{ABO}$-Rhesus blood group and PPCM. Consequently, the present study assessed the distribution of the different ABO-Rh groups among ninety patients diagnosed with PPCM from three centres in Sokoto metropolis.
\end{abstract}

Methods: Records from ninety (90) consecutive consenting patients were analyzed for this study. Data included were demographic, Clinical, Electrocardiographic and Echocardiographic. Data analysis was carried out using IBM SPP software. Values were expressed as mean \pm standard deviation (SD), as well as tables of frequencies. Where relationships for non-parametric data were sought, chi-square goodness of fit was estimated. Single factor ANOVA was used to determine difference in means among the different blood groups, using Microsoft excel. P-value of $\leq 0.05$ was considered statistically significant.

Results: The mean age of the study participants was 27.2 \pm 8.2 years, with range 1745 years. About $55.1 \%$ of the patients enrolled in the study are of Blood group B, Blood group $O$ constitute $30.8 \%$, while groups $A$ and $A B$ form a paltry $14.1 \%$ of the study population $\left(X^{2}=52.99, P<0.0001\right.$, $\mathrm{df}=3$ ). About $86.6 \%$ of the patients had ejection fraction (EF) below $45 \%$, with mean value of $36.70 \pm 7.52 \%$. Mean EFs for the groups were $35.46 \pm 8.05,37.09 \pm 8.12,36.00$ \pm 4.36 and $36.98 \pm 6.81$ for $A, B, A B$ and $O$ respectively $(F$ $=0.1399$, Fcrit $=2.7159, \mathrm{df}=3, \mathrm{P}=09358) .93 .3 \%$ of the

Citation: Umar H, Isezuo SA, Usman MZ, Yusuf AA, Umar BT, et al. (2020) ABO-Rhesus Blood Group Distribution among Peri-Partum Cardiomyopathy Patients: A Multi-Center Study in Sokoto, Nigeria. Int J Clin Cardiol 7:182. doi.org/10.23937/2378-2951/1410182

Accepted: June 10, 2020; Published: June 12, 2020

Copyright: (c) 2020 Umar H, et al. This is an open-access article distributed under the terms of the Creative Commons Attribution License, which permits unrestricted use, distribution, and reproduction in any medium, provided the original author and source are credited. 
patients are multiparous and $7.8 \%$ of them had multiple gestations. About $94.3 \%$ of the patients had sinus tachycardia, with mean HR of $116.33 \pm 11.03 \mathrm{bpm}$.

Conclusion: We observed that blood group B may be a risk factor for the development of PPCM among women of childbearing age in our setting, even though over half of the general population is of the $\mathrm{O}$ blood group. However, the mechanism by which this happens may require further studies. Nevertheless, pregnant women of blood group B, with other risk factors for PPCM may require additional specialist attention to forestall clinical PPCM.

\section{Keywords}

Peripartum cardiomyopathy, ABO-Rhesus blood group, Multicentre

\section{Introduction}

Peripartum cardiomyopathy (PPCM) is a major cause of death in women of childbearing age globally [1-3]. Earlier studies on PPCM were unequivocal on the preponderance of the cases in Northern Nigeria [2,4]. The prevalence of PPCM is increasing in sub-Saharan Africa [2]. It was reported to be associated with $60 \%$ of heart failure admissions and responsible for over $30 \%$ of cardiac deaths in a tertiary hospital in Northwest Nigeria [3]. Similarly, PPCM was responsible for $17 \%$ to $34 \%$ of maternal mortality in South Africa [1,5]. Although, there are established treatment protocols for PPCM, the Nigerian health financing system is still poorly structured and most patients have to pay out-of-pocket to access care [6]. Additionally, some of the conventional medications used in management of heart failures are associated with undesirable side effect in pregnancy and during lactation [5]. To this extent therefore, it will be an important strategy in our setting to identify the risk factors for PPCM so as to avert its occurrence [5].

The association of ABO-Rhesus blood group system with cardiovascular diseases is an area receiving increasing interest [7-9]. The ABO blood group system, a well-known genetic risk factor, demonstrated clinically to be linked with thrombotic vascular diseases, is associated with the risk of coronary artery disease (CAD) and hypertrophic cardiomyopathy $(\mathrm{HCM})[7,8]$. In this regard, the $O$ blood group was reported to have shown less risk for cardiovascular diseases aetiopathogenesis compared to the non-O groups [7-9]. Indeed, blood group $B$ in the males have been shown to be associated with increased left ventricular outflow tract gradient and ejection fraction but with worse New York Hear Associations classes, of in the ranges IV and $V$ [8]. The $A B O$ antigens are expressed not only on the surface of blood cells but also on variety of human tissues including, cardiac tissue, endocardium, epithelia and vascular endothelia [7]. In view of these findings, it is reasonable to hypothesize that such carbohydrate moieties are of importance not only in transfusion and transplantation medicine but also for the pathogenesis of various systemic diseases and possibly cardiomyopathies $[10,11]$.
Earlier studies made efforts to identify the risks factors for cardiac diseases in the reproductive age, including a study that showed association between $A B O$ blood groups and the risk of $C A D[7,10]$. An individual may have type $A$, type $B$, type $O$, or type $A B$ blood group and this arise from inheriting one or more of the alternative 3 main alleles two co- dominant ( $A$ and $B$ ) and one recessive (0) [12].

The role of $A B O$ blood group antigens in the aetiopathogenesis of various cardiovascular diseases is a fascinating subject and may serve as impetus for developing novel strategies for possible reduction of global burden of cardiovascular diseases in the near future. Consequently, the present study determined the distribution of $\mathrm{ABO}$-Rhesus blood group classes among PPCM patients in Sokoto, North-Western Nigeria and observed differences in the distributions in the national average and from local data among female populations.

\section{Methods}

\section{Study sample information}

The study was approved by the ethics review committees of the Usmanu Danfodiyo University Teaching Hospital, Sokoto (UDUTH/HREC/2017/No.840), Specialist Hospital Sokoto (SHS/SUB/133/VOL.1) and Medistop Clinical Diagnostic Center (MCD/SUB/012/VOL.1) All the eligible participants who enrolled in the study gave their informed written consents. Regulations concerning human research, as enshrined in the Helsinki declaration [13] were complied with. The patients enrolled were seen at the above three health centres, between January 2018 and June 2019. One hundred and ten (110) consecutive patients were enrolled, who fulfilled the European Society of Cardiology (ESC) diagnostic criteria for PPCM [5,14] were enrolled. Subjects were, aged 15 years and older, seen at the above mentioned health facilities. Ninety (81.8\%) participants eventually qualified for the study. A well-structured questionnaire was administered to each participant and information collated included demographic, clinical features, past medical history and relevant pregnancy related cultural practices such as traditional hot bath and ingestion of pap made with millet and enriched with in dry lake salt ("Kununkanwa" in Hausa). In addition, files of one hundred and five healthy women, who had their antenatal and postnatal cares at UDUTH were retrieved and analyzed for comparisons with the PPCM patients.

Patients with poor echo windows, with known history of alcoholism, diabetes mellitus, hypertension, thyrotoxicosis, sickle cell anemia, rheumatic heart disease were excluded from the study.

\section{Statistical analysis}

Data storage and analysis was completed with IBM SPSS software (version 22 for windows Inc., Chicago, IL, USA). Exploratory data analysis was performed to de- 
tect incorrect entries and normality was examined using Shapiro-Wilk test. Mean and standard deviations were computed for quantitative variables and non-parametric equivalents were used for qualitative variables. Chi-square goodness of fit analysis was used to ascertain that the ABO-Rhesus groups distribution among the PPCM patients was not an incidental occurrence. A two-sided $P$-value of $<0.05$ was considered as minimum level statistical significance.

\section{Clinical information}

After recruitment of each patient, detailed clinical evaluation was carried out as follows:

- Symptoms suggestive of left-sided heart failure were evaluated, these included dyspnea on exertion and at rest, cough (dry or productive of whitish frothy sputum), hemoptysis, nocturnal cough, easy fatigability, paroxysmal nocturnal dyspnea (PND), orthopnea, chest pain and palpitation.

- Symptoms of right-sided heart failure were evaluated. These, these included e.g leg swelling, progressive abdominal swelling, easy satiety, right hypochondrial pain/discomfort.

- Precipitating factors of heart failure (HF) were evaluated. These included chest infections, anaemia and arrhythmias.

- Other underlying causes of HF and previous diagnosis of hypertension: valvular heart disease, congenital heart disease, coronary heart disease or chronic medical condition: e.g chronic liver disease, chronic kidney disease or respiratory diseases were all ruledout in the patients.

\section{General physical and systemic examination}

- New York Heart Association (NYHA) heart failure functional classes were determined at the time of first contact.

- The radial pulse was assessed.

- Brachial blood pressure was measured, using Accuson mercury sphygmomanometer with an appropriate cuff on the left or right arm. The average of three readings were taken as the Systolic and diastolic blood pressures, respectively at $1^{\text {st }}$ and $5^{\text {th }}$ Korotkoff sounds, in sitting position after five minutes of rest with the arm at pressure reference point (PRP) and readings taken to the nearest $2 \mathrm{mmHg}$ [15].

- Presence of raised jugular venous pressure (JVP), apex beat, character, thrills, third heart sound (S3) gallop, variability of first heart sound (S1), loud second heart sound pulmonary component (P2), murmurs, respiratory rate, oxygen saturation, bi-basal fine or coarse crepitations, signs of pleural effusion were assessed.

- Pitting pedal edema, congestive hepatomegaly and ascites were assessed.

- Anthropometric measurements e.g weight, height, body mass index (BMI), body surface area (BSA) were determined using standard procedures.

\section{Electrocardiography}

Electrocardiography (ECG) was performed with cardiofax ECG machine. The recommendation of the American Heart Association (AHA) [16], concerning standardization of the leads and specification for instrument was followed and relevant abnormal findings were noted for each subject. Standard resting 12 lead ECG were recorded as $25 \mathrm{~mm}$ per second and $1 \mathrm{Mv}$ per $\mathrm{cm}$ standardization. Atrial and ventricular heart rates, rhythm, $\mathrm{P}$ wave, P-R interval and QRS duration abnormalities were noted. QRS axis in frontal plane directed to the region between $-30^{\circ}$ to $105^{\circ}$ was taken as normal axis and QT interval corrected to heart rate (QTc) were as well measured and noted.

\section{Echocardiography}

Echocardiographic examination was performed with the patient in the left lateral decubitus position using Sonascape SSI-5000 ultrasound imaging system with a 3.5 MHz transducer. Two-dimensional (2-D) guided M-mode and Doppler studies were obtained with transthoracic echocardiography (TTE). Measurements were obtained in accordance with the recommendation of the American Society of Echocardiography (ASE) [17] with leading edge to leading edge recordings taken. Calculations were made using the inbuilt analysis software of the echocardiographic machine. The 2-D views were used for real time morphological characteristics and also as a reference for selection of the $\mathrm{M}$-mode beam. The echo views utilized for the study included parasternal long axis view, short axis view, apical 4-chamber view, and 5 chamber view. These views and measurements were used to examine pericardial and cardiac cavity, wall dimensions, aortic dimension, wall motion abnormalities, valve morphology, motion and dimension, chamber dimensions and appearance as well as systolic function; intramural thrombus, septal defect, valvular vegetations were all looked for. Recording of the mitral inflow were obtained from apical 4-chamber view in order to assess left ventricular (LV) filling dynamics. The diastolic function was determined by the E/A ratio which is the ratio of peak early transmitral filling velocity (E) and late transmitral filling velocity $(A)$, as well as the deceleration time and Isovolumic relaxation time. The presence and magnitude of regurgitation across heart valve was assessed by color Doppler echocardiography.

\section{ABO/Rhesus blood grouping}

Blood groups were determined from venous blood samples through the Ag-Ab agglutination method using monoclonal $\mathrm{ABO} / \mathrm{Rh}$ blood grouping reagents using tile technique. The reagent kits were manufactured by CLAS 
Table 1: Characteristics of the study population.

\begin{tabular}{|c|c|}
\hline Demographic variables $(n=90)$ & Frequency (\%) \\
\hline Mean age \pm SD (years) & $27.2 \pm 8.2$ \\
\hline \multicolumn{2}{|l|}{ Parity } \\
\hline Para 1 & $6(6.7)$ \\
\hline Para 2 & $55(61.1)$ \\
\hline Para 3 & $18(20.0)$ \\
\hline Para 4 & $7(7.8)$ \\
\hline Para 5 & $3(3.3)$ \\
\hline$\geq$ Para 6 & $1(1.1)$ \\
\hline \multicolumn{2}{|l|}{ Occupation } \\
\hline Unemployed & $89(98.8)$ \\
\hline Civil servant & $1(1.2)$ \\
\hline \multicolumn{2}{|l|}{ Marital status } \\
\hline Married & $87(96.3)$ \\
\hline Divorced & $3(3.7)$ \\
\hline \multicolumn{2}{|l|}{ Education status } \\
\hline Tertiary & $4(4.7)$ \\
\hline Secondary & $8(9.3)$ \\
\hline Primary & $10(11.6)$ \\
\hline Quranic & $67(74.4)$ \\
\hline \multicolumn{2}{|l|}{ Tribe } \\
\hline Hausa/Fulani & $89(98.7)$ \\
\hline Others & $1(1.3)$ \\
\hline \multicolumn{2}{|l|}{ Religion } \\
\hline Islam & $88(97.6)$ \\
\hline Christianity & $2(2.4)$ \\
\hline \multicolumn{2}{|l|}{ Patient status } \\
\hline Inpatient & $69(76.7)$ \\
\hline Outpatient & $21(23.3)$ \\
\hline \multicolumn{2}{|l|}{ Traditional practices } \\
\hline Hot water bath & $9(9.9)$ \\
\hline Hot water bath and Potash pap & $70(77.8)$ \\
\hline None & $11(12.3)$ \\
\hline \multicolumn{2}{|l|}{ History of pre-eclampsia } \\
\hline Yes & $1(1.1)$ \\
\hline No & 89 (98.9) \\
\hline \multicolumn{2}{|l|}{ Outcome } \\
\hline Alive & $86(95.6)$ \\
\hline Dead, in-hospital & $4(4.4)$ \\
\hline
\end{tabular}

technology (United Kingdom). This involved mixing of one drop of PPCM subjects' whole blood with a drop each of commercially obtained anti-A, Anti-B, Anti-AB, and Anti-D antisera on plastic tile. Using a glass rod, blood cells and sera were mixed, and the tile rocked gently for about a minute. Agglutinations were determined after 3-5 minute by inspection of the admixture. When in doubt, agglutinations were sorted out microscopically or further confirmed by serum reversed grouping using known group $A$ and $B$ cells.

\section{Other relevant investigations}

Hemogram ( $\mathrm{Hb})$, Fasting blood sugar (FBS), Fasting lipid profile (FLP), and serum urea, electrolyte and creatinine were also done in addition to Chest X-ray (PA
Table 2: Severity of LV systolic dysfunction using EF.

\begin{tabular}{|l|l|}
\hline Variable & Frequency (\%) \\
\hline Normal (EF > 55\%) & - \\
\hline Mild (EF 45\%-54\%) & $12(13.3)$ \\
\hline Moderate (EF 30\%-44\%) & $59(65.5)$ \\
\hline Severe (EF < 30\%) & $19(21.1)$ \\
\hline
\end{tabular}

LV: Left Ventricle; EF: Ejection Fraction

view).

\section{Diagnosis of PPCM}

Diagnosis of PPCM was made based on the European Society of cardiology diagnostic criteria for PPCM [5,14].

\section{Results}

The mean age of the subjects was $27.2 \pm 8.2$ years, with range $17-45$ years, which match the age of the control pregnant women $(n=105), 26.28 \pm 5.23$ years, range $18-40$ years $(p=0.073)$. Most of the patients are of the Hausa/Fulani extraction, unemployed, married and majority of them (74.4\%) without formal education. Majority of the patients are also multiparous and seven $(7.8 \%)$ of the patients had multiple gestation (Table 1$)$.

In this study, about $86.6 \%$ of the study group have LVEF below $45 \%$ and about $13.31 \%$ of them have LVEF between $45 \%-50 \%$ (Table 2). The mean LVEF for the patients was $36.70 \pm 7.52 \%$.

Both the QRS complex and QT corrected to heart rate (QTc) durations in the study population were within normal ranges and they are respectively $89.02 \pm 15.14$ $\mathrm{ms}$ and $447.67 \pm 90.10 \mathrm{~ms}$. However, they exhibited sinus tachycardia in the majority $(94.3 \%, 85 / 90)$, with average HR of $116.33 \pm 11.03 \mathrm{bpm}$. Most participants $(96.3 \%)$ presented with signs and symptoms in keeping with PPCM within 5 months following child delivery. And, during the same time frame, most $(70.7 \%)$ of the patients reported to have experienced severe exercise intolerance and breathlessness, even at rest. Most of the patients (96.7\%) experienced PND, 98.9\% developed bilateral leg swellings and most of them demonstrated raised JVP (Table 3 ).

Blood group $\mathrm{B}^{+}$is the most preponderant of the $\mathrm{ABO}$ Rh system among the patients and constitute over half of the sampled population (50/90), followed by blood group $\mathrm{O}^{+}(28 / 90)$ and remaining $12 / 90$ for blood groups $\mathrm{A}^{+}$and $\mathrm{AB}^{+}\left(\chi^{2}=77.45, \mathrm{df}=3, \mathrm{P}<0.0001\right)$ (Figure 1 and Table 4).

The mean EF of the groups are $35.46 \pm 8.05,37.09$ $\pm 8.12,36.00 \pm 4.36$ and $36.98 \pm 6.81$ for the $A, B, A B$ and $O$ groups, respectively, which were not significantly different from each other $(F=0.1399$, Fcrit $=2.7159$, df $=3, P=0.9358$ ).

\section{Discussions}

The key findings in the present study are; majority 
Table 3: Spectrum of clinical history, relevant physical examination and ECG findings of the study population.

\begin{tabular}{|c|c|}
\hline Clinical variables $(n=90)$ & Frequency (\%) \\
\hline $\begin{array}{l}\text { Onset of HF symptoms } \\
\text { Last month of pregnancy } \\
\text { Within six months post-delivery }\end{array}$ & $\begin{array}{l}2(2.2) \\
88(97.8)\end{array}$ \\
\hline $\begin{array}{l}\text { NYHA class } \\
\text { Class I } \\
\text { Class II } \\
\text { Class III } \\
\text { Class IV }\end{array}$ & $\begin{array}{l}0(0.0) \\
5(5.6) \\
22(24.4) \\
63(70.0)\end{array}$ \\
\hline $\begin{array}{c}\text { Dyspnoea } \\
\text { Yes } \\
\text { No }\end{array}$ & $\begin{array}{l}90(100.0) \\
0(0)\end{array}$ \\
\hline $\begin{array}{l}\text { Cough } \\
\text { Yes } \\
\text { No }\end{array}$ & $\begin{array}{l}87(96.7) \\
3(3.3)\end{array}$ \\
\hline $\begin{array}{l}\text { Easy fatigue } \\
\text { Yes } \\
\text { No }\end{array}$ & $\begin{array}{l}87(96.7) \\
3(3.3)\end{array}$ \\
\hline $\begin{array}{l}\text { Hemoptysis (blood stained } \\
\text { sputum) } \\
\text { Yes } \\
\text { No }\end{array}$ & $\begin{array}{l}43(48.3) \\
47(51.7)\end{array}$ \\
\hline $\begin{array}{l}\text { Orthopnea } \\
\text { Yes } \\
\text { No }\end{array}$ & $\begin{array}{l}79(87.8) \\
11(12.2)\end{array}$ \\
\hline $\begin{array}{l}\text { PND } \\
\text { Yes } \\
\text { No }\end{array}$ & $\begin{array}{l}87(96.7) \\
3(3.3)\end{array}$ \\
\hline $\begin{array}{l}\text { Leg swelling } \\
\text { Yes } \\
\text { No }\end{array}$ & $\begin{array}{l}89(98.9) \\
1(1.1)\end{array}$ \\
\hline $\begin{array}{l}\text { Abdominal swelling } \\
\text { Yes } \\
\text { No }\end{array}$ & $\begin{array}{l}83(92.2) \\
7(7.8)\end{array}$ \\
\hline $\begin{array}{l}\text { Easy satiety } \\
\text { Yes } \\
\text { No }\end{array}$ & $\begin{array}{l}63(70.1) \\
27(29.6)\end{array}$ \\
\hline $\begin{array}{l}\text { Right hypochondria pain } \\
\text { Yes } \\
\text { No }\end{array}$ & $\begin{array}{l}58(64.2) \\
32(35.8)\end{array}$ \\
\hline $\begin{array}{l}\text { History of pre-partum } \\
\text { haemorrhage } \\
\text { Yes } \\
\text { No }\end{array}$ & $\begin{array}{l}8(8.6) \\
82(96.3)\end{array}$ \\
\hline $\begin{array}{l}\text { Multiple gestation } \\
\text { Yes } \\
\text { No }\end{array}$ & $\begin{array}{l}7(7.8) \\
83(92.2)\end{array}$ \\
\hline $\begin{array}{l}\text { History of post-partum } \\
\text { haemorrhage } \\
\text { Yes } \\
\text { No }\end{array}$ & $\begin{array}{l}5(5.6) \\
85(94.4)\end{array}$ \\
\hline Pulse rate \pm SD (bpm) & $116.3 \pm 11.0$ \\
\hline
\end{tabular}

\begin{tabular}{|c|c|}
\hline SBP \pm SD $(\mathrm{mmHg})$ & $108.7 \pm 14.9$ \\
\hline $\mathrm{DBP} \pm \mathrm{SD}(\mathrm{mmHg})$ & $74.6 \pm 13.0$ \\
\hline \multicolumn{2}{|l|}{ JVP } \\
\hline Raised & $73(83.9)$ \\
\hline Not raised & $14(16.1)$ \\
\hline \multicolumn{2}{|l|}{ Displaced apex } \\
\hline Displaced & $86(95.4)$ \\
\hline Not displaced & $4(4.6 \%)$ \\
\hline \multicolumn{2}{|l|}{ S3 gallop } \\
\hline Present & $85(94.4)$ \\
\hline Absent & $5(5.6)$ \\
\hline \multicolumn{2}{|l|}{ Murmur } \\
\hline Mitral regurgitant & $29(32.2)$ \\
\hline Tricuspid regurgitant & $0(0)$ \\
\hline Mitral and tricuspid regurgitant & $9(10.0)$ \\
\hline Absent murmur & $52(57.8)$ \\
\hline \multicolumn{2}{|l|}{ Pitting pedal oedema } \\
\hline Present & $83(92.2)$ \\
\hline Absent & $7(7.8)$ \\
\hline \multicolumn{2}{|l|}{ Hepatomegaly } \\
\hline Present & $80(88.9)$ \\
\hline Absent & $10(11.1)$ \\
\hline \multicolumn{2}{|l|}{ Demonstrable ascites } \\
\hline Present & $82(91.1)$ \\
\hline Absent & $8(8.9)$ \\
\hline $\begin{array}{l}\text { Pattern of ventricular HF at } \\
\text { presentation }\end{array}$ & $84(93.3)$ \\
\hline BVHF & $6(6.7)$ \\
\hline \multicolumn{2}{|l|}{ LVHF } \\
\hline \multicolumn{2}{|l|}{ Low QRS voltage } \\
\hline Present & $70(78.0)$ \\
\hline Absent & $20(22.0)$ \\
\hline \multicolumn{2}{|l|}{ LVH } \\
\hline Present & $13(14.0)$ \\
\hline Absent & $77(86.0)$ \\
\hline
\end{tabular}

BMI: Body Mass Index; BSA: Body Surface Area; NYHA: New York Heart Association; PND: Paroxysmal Nocturnal Dyspnea; JVP: Jugular Venous Pressure; HF: Heart failure; LVHF: Left Ventricular Heart Failure; BVHF: Biventricular Heart failure; LVH: Left Ventricular Hypertrophy

of the patients are of blood group B'followed by blood group 0 . This is in sharp contrast to the distribution of ABO-Rhesus blood group known globally. The Nigerian national data (comprising both males and females or the average for the female alone) showed the dominance of the O-group to about half the population, followed by each of $A$ and $B$ in similar proportions (21\%-23\%), then $A B$-group constituting about $2 \%-3 \%$ of the population. Similarly, a local data obtained from the files of healthy pregnant women who had their antenatal and postnatal cares in the tertiary health centre where most of the PPCM were recruited was also consistent with both the national and global distributions of the blood group as captured in Table 4. 
Table 4: The distributions of the different ABO-Rhesus blood groups among the general population in Nigeria, compared with the distribution among healthy female controls and patients with PPCM in Sokoto, Northwestern Nigeria.

\begin{tabular}{|l|l|l|l|l|}
\hline Blood group & $\begin{array}{l}\text { \% National average } \\
\text { (males + females) }\end{array}$ & $\begin{array}{l}\% \text { National average } \\
\text { (females only) }\end{array}$ & $\begin{array}{l}\text { \% distribution among } \\
\text { female controls in Sokoto }\end{array}$ & $\begin{array}{l}\text { \% Distribution among } \\
\text { PPCM patients in Sokoto }\end{array}$ \\
\hline A & 20.78 & 20.50 & 26.7 & 10.3 \\
\hline B & 23.50 & 20.70 & 21.9 & $55.1^{* * *}$ \\
\hline AB & 3.18 & 1.60 & 1.9 & 3.8 \\
\hline O & 51.91 & $57.20^{* *}$ & 49.5 & 30.8 \\
\hline
\end{tabular}

(Adeyemo and Soboyejo, [18]; Egesie, et al. [19]; Jeremiah [20])

${ }^{* *}=p<0.005 ;{ }^{* * *}=p<0.0001$

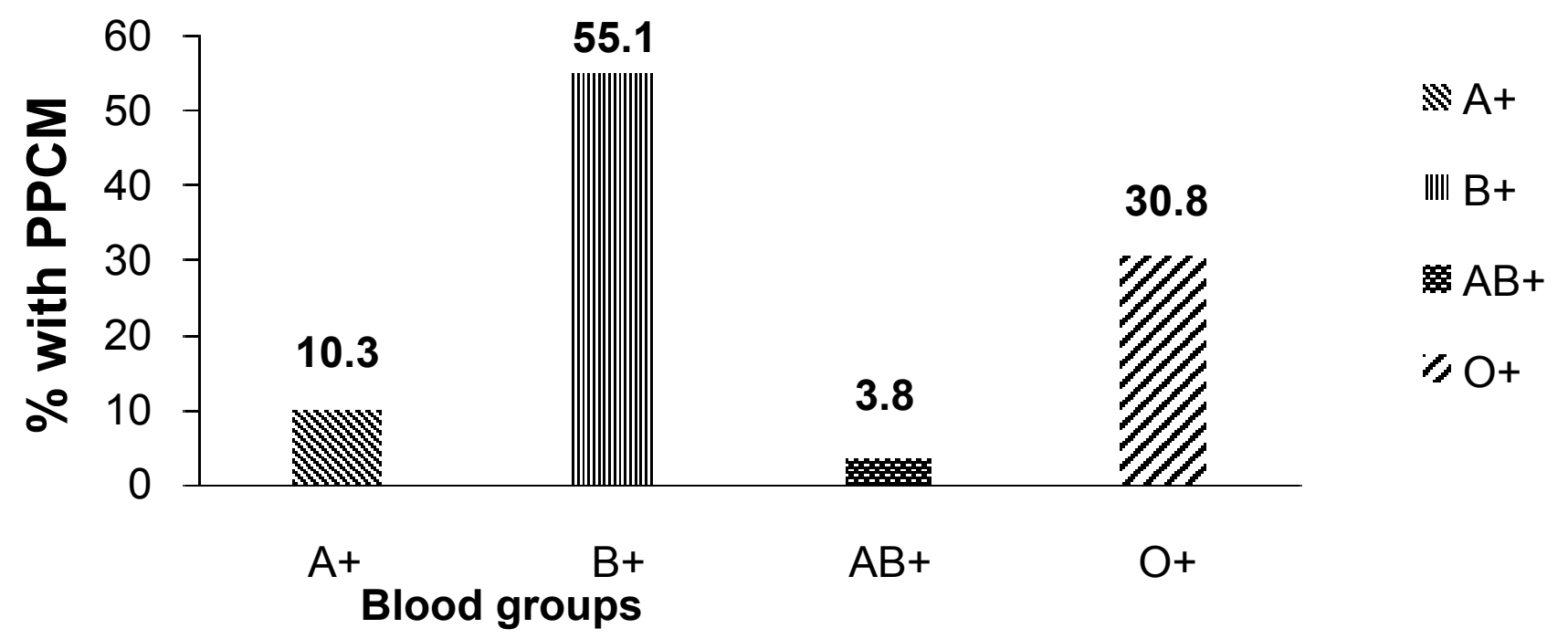

Figure 1: Distribution of $A B O-R h e s u s$ blood groups among patients with PPCM.

Table 5: Frequencies of parity, hypertension, multiple gestation, maternal age and history of pre-eclampsia in the present study group.

\begin{tabular}{|c|c|c|c|c|c|}
\hline & Present study (\%) & Reference study (\%) & Chi-squared $\left(x^{2}\right)$ & Degree of freedom (df) & P-value \\
\hline \multicolumn{6}{|l|}{ Parity } \\
\hline$\leq 1$ & 6.7 & 20 & \multirow[b]{2}{*}{11.06} & \multirow[b]{2}{*}{1} & \multirow[b]{2}{*}{$<0.0001$} \\
\hline$>1$ & 93.3 & $\begin{array}{l}80 \\
\text { Sliwa, et al. [21] }\end{array}$ & & & \\
\hline \multicolumn{6}{|l|}{ SBP } \\
\hline$\geq 140 \mathrm{mmHg}$ & 4.8 & 37 & \multirow[b]{2}{*}{40.24} & \multirow[b]{2}{*}{1} & \multirow[b]{2}{*}{$<0.0001$} \\
\hline$<140 \mathrm{mmHg}$ & 95.2 & $\begin{array}{l}63 \\
\text { Bello, et al. [32] }\end{array}$ & & & \\
\hline \multicolumn{6}{|l|}{ Multiple gest } \\
\hline Yes & 7.8 & 14.5 & \multirow[b]{2}{*}{3.62} & \multirow[b]{2}{*}{1} & \multirow[b]{2}{*}{0.0571} \\
\hline No & 92.2 & $\begin{array}{l}85.5 \\
\text { Karaye, et al. [31] }\end{array}$ & & & \\
\hline \multicolumn{6}{|l|}{ Mat age } \\
\hline$<35$ yrs & 76.5 & 71 & \multirow[b]{2}{*}{1.35} & \multirow[b]{2}{*}{1} & \multirow[b]{2}{*}{0.2449} \\
\hline$\geq 35$ yrs & 23.5 & $\begin{array}{l}29 \\
\text { Lee, et al. [30] }\end{array}$ & & & \\
\hline \multicolumn{6}{|l|}{ PET } \\
\hline Yes & 1.1 & 22 & \multirow[b]{2}{*}{23.21} & \multirow[b]{2}{*}{1} & \multirow[b]{2}{*}{$<0.0001$} \\
\hline No & 98.9 & $\begin{array}{l}78 \\
\text { Bello, et al. [32] }\end{array}$ & & & \\
\hline
\end{tabular}

SBP: Systolic Blood Pressure; Multiple gest: Multiple gestation; Mat age: Maternal age; PET: Pre-eclampsia 
Most of the patients are also multiparous with those with primipara constituting a small percentage $(6.7 \%)$ of the study population. Majority of the patients are of the normal systolic blood pressure (SBP) range $(<$ $140 \mathrm{mmHg}$ ). Only about 4.8\% (4/90) of them have SBP above $140 \mathrm{mmHg}$. However, 93.7\% (84/90) of the patients had heart rate (HR) above $100 \mathrm{bpm}$. About $13.3 \%$ of the patients had EF between $45 \%$ and $50 \%$. Although, HFrEF is a hallmark of PPCM, some patients of PPCM may present with $\mathrm{EF}$ between $45 \%-50 \%$ [5]. And $84.3 \%$ of the subjects have BMI below $25 \mathrm{~kg} / \mathrm{m}^{2}$. Mean BMI for the study population was $21.42 \pm 3.43 \mathrm{~kg} / \mathrm{m}^{2}$.

Our patients exhibited some known concomitants of PPCM as observed by earlier studies [5,22,23], notably sinus tachycardia, low QRS voltage and a small proportion of LVH (Table 3).

Consistent with global data, blood group O constitute the dominant blood group under the ABO-Rhesus system in Sokoto, Northwestern Nigeria $[24,25]$ and it's followed by the A and B blood groups. Similarly, the pattern of $A B O-R h e s u s$ group distribution among females is the same as found among the general population in Nigeria $(P>0.05)[19,20,26]$. However, this phenomenon seems to be reversed despite there is no known exclusion criteria or factors, including demographic or clinical that could be identified to have influenced this outcome, rather than possible genetical basis. In this regard, it is unlikely that any particular blood group might have been affected by the selection procedure, because blood group-O known to have low risk of cardiovascular diseases, for possessing glycotransferases enzymes that proffer this benefit on it bearers [27] still appeared prominent in the distribution. Similarly, group-A which is known to have similar preponderance with $B$, trailed by only one-fifth the proportion of B-group in this PPCM patients. Furthermore, Hausa/Fulani ethnic group, which is the majority in Sokoto, considered alone from the 105 control females data from one of the recruitment centers, has similar distribution as the national data: $A(26.7 \%$ vs. $25.3 \%)$, B ( $21.9 \%$ vs. $26.7 \%)$, AB (1.9\% vs. $2.7 \%)$ and $O(49.5 \%$ vs. $45.3 \%)$, for the female control and Hausa/Fulani sub-control group respectively, $\chi^{2}$ $=1.8187, \mathrm{df}=3$ and $\mathrm{P}=0.6109$. Moreover, analyzing the data as B-group against non-B group, still showed significant proportion of PPCM patients with B-group: B-group against non-B groups, PPCM (observed), vs. control (expected) are, B (55.1\% vs. $21.9 \%)$ and non-B (44.9\% vs. $78.1 \%$ ), $\chi^{2}=64.4438, D f=1, P<0.001$.

Furthermore, while group-O individuals have lower risk of developing cardiovascular diseases, A and B group are deficient in the glycotranferases enzymes that encodes for such protection [27]. Indeed, O group shows less of cardiovascular risks, $A$ and $B$ groups have more tendencies to develop myocardial infarctions and $C A D$, but $A B$-group shows better survival from cardiac procedures, as well as all critical illnesses $[8,9,27,28]$.
Moreover, five out of seven (71.4\%) of our patients who had multiple gestations are of blood group $\mathrm{B}^{+}$and the remaining two are of blood group $\mathrm{O}^{+}$.

The pathogenesis of cardiomyopathy has been shown by earlier studies to have genetic basis $[5,27]$. In this regard, as much as $20 \%$ of patients with PPCM have been reported to bear some mutant genes making them vulnerable to the disease $[5,27]$. Similarly, the ABO-Rhesus blood group type expressed by any individ$u a l$ is genetically determined $[11,27]$. The different $A B O$ blood groups and the complimentary Rhesus factors may connote different levels of susceptibilities to both infectious and noninfectious diseases $[11,28]$. However, in the present study only one patient $(1.2 \%)$ is Rhesus negative and is unlikely to influence the overall results $\left(\chi^{2}=1.45, d f=1, p=0.2283\right)$. Indeed, Rhesus negativity is rare in our setting $[19,20,24]$. Therefore, whether the mutant genes that are linked to some PPCM have predilections for blood group $\mathrm{B}^{+}$, need further studies.

Although the present population of PPCM patients studied are all of black African descent, some risk factors (hypertension, PET) which earlier studies observed to be associated with PPCM $[1,5,14]$, are only present to a lesser proportions in the present study. Most of the patients are below the age of 35 years, similar to what Lee and colleagues reported in South Korea. But our patients have lower mean age ( $32.1 \pm 4.3$ years vs. $27.2 \pm$ 8.2 years) and this may not be unconnected to the norm in the Hausa/Fulani ethnic group, where cultural and religious reasons women are married out at earlier ages [29]. In the present study, multiple gestation and maternal age groups showed similar preponderances with earlier studies [30,31] (Table 5). Furthermore, we've reported a substantially lower number of subjects with SBP lower than $140 \mathrm{mmHg}$ compared to earlier study by our group Isezuo and Abubakar [3] and history of pre-eclampsia compared to what were reported elsewhere $[30,32]$. Multiparity showed high preponderance among our patients, similar to what was reported by Sliwa, et al. [21] and cited by the study [32], but in the present study, there was more preponderance. Therefore, the influences of some of these factors on the disease phenotype here could not be guaranteed. Indeed, it informed the reason why more risk factors for the development of PPCM in the black women population need to be sought for.

\section{Novelty of the Present Study}

The present study is the first, from our literature search, to report the preponderance of Blood group B among PPCM patients (even though the preponderant blood group is $\mathrm{O}$, in the general population as well as in the national and local female populations) of black African descent, and especially Northwest Nigeria, being the 'hot spot' for the disease, the world over. And this is importantly so, as some of the common risk factors of PPCM among blacks were absent in the present data 
and a compelling reason to seek for other risk factors for PPCM.

\section{Limitations of the Study}

The sample size in the present study is small, considering how preponderant PPCM is in Northwestern Nigeria. We are also not empowered with the necessary facilities to ascertain the genetic polymorphism that may be responsible for blood group $B$ individuals.

\section{Conclusions}

PPCM is an important cause of morbidity and mortality among women of child bearing age. While there are efficient pharmacological agents for managing HFrEF, as typical of PPCM, some of these compounds may not be suitable for use in pregnancy or during breastfeeding. There is a possibility of identifying individuals who are susceptible to developing PPCM even though they are clinically normal. Risk determination among pregnant women for PPCM is therefore warranted, as most patient still pay out of pocket for medical services in Nigeria, on a background poor per capita income [6]. Consequently, this study observed that most of the PPCM studied are of the blood group $B$, even though the predominant blood group type in the general population here is the $\mathrm{O}$ group, with $\mathrm{B}$ group having only about half the proportion of $\mathrm{O}[24,33]$. To this extent therefore, we conclude that blood group $B$ may be an additional risk factor for PPCM in women of child bearing age, and may require more specialist attention during perinatal period, compared to other women with similar risk of PPCM. We recommend a large-scale multicenter study in the general population to ascertain the genetic polymorphism in female individuals with $B$ blood group that makes them more susceptible to PPCM than others.

\section{Acknowledgement}

We sincerely appreciate our patients who participated in the study. The medical house officers were also helpful during sample collections, we thank them too. Mr. Jonathan Isiah is profoundly thanked, for the technical assistance with the electrocardiography.

\section{Conflict of Interest}

None declared.

\section{Sources of Funding}

No funding from any source.

\section{Authors Contribution to the Manuscript}

All authors contributed equally, from the research design up till the final form of the manuscript.

\section{References}

1. Soma-Pillay P, Seabe J, Sliwa K (2016) The importance of cardiovascular pathology contributing to maternal death: Confidential enquiry into maternal deaths in South Africa, 2011-2013. Cardiovasc J Afr 27: 60-65.
2. Danbauchi S, Oyati A, Isa M, Alhassan M (2014) Peripartum cardiomyopathy. Nigerian Journal of Cardiology 11: 66-73.

3. Isezuo SA, Abubakar SA (2007) Epidemiologic profile of peripartum cardiomyopathy in a tertiary care hospital. Ethn Dis 17: 228-233.

4. Danbauchi SS (2002) Echocardiographic features of peripartum cardiac failure: The Zaria syndrome. Trop Doct 32: 24-27.

5. Bauersachs J, König T, van der Meer P, Petrie MC, Hilfiker-Kleiner D, et al. (2019) Pathophysiology, diagnosis and management of peripartum cardiomyopathy: A position statement from the Heart Failure Association of the European Society of Cardiology Study Group on peripartum cardiomyopathy. Eur J Heart Fail 21: 827-843.

6. Ogah OS, Stewart S, Onwujekwe OE, Falase AO, Adebayo SO, et al. (2014) Economic burden of heart failure: Investigating outpatient and inpatient costs in Abeokuta, Southwest Nigeria. PLoS One 9: e113032.

7. Franchini M, Liumbruno GM (2013) ABO blood group: Old Dogma, new perspectives. Clin Chem Lab Med 51: 15451553.

8. Jiang X, Yuan J, Cui J, Liu S, Hu F, et al. (2018) Blood type $B$ antigen is associated with worse New York Heart Association classification in male patients with hypertrophic cardiomyopathy. Anatol J Cardiol 20: 258-265.

9. He M, Wolpin B, Rexrode K, Manson JE, Rimm E, et al. (2012) ABO blood group and risk of coronary heart disease in two prospective cohort studies. Arterioscler Thromb Vasc Biol 32: 2314-2320.

10. Liumbruno GM, Franchini M (2013) Beyond immunohaematology: The role of the $A B O$ blood group in human diseases. Blood Transfus 11: 491-499.

11. Mattos LCde, Moreira HW (2004) Genetic of the ABO blood system and its link with the immune system. Rev Bras Hematol Hemoter 26: 60-63.

12. Storry JR, Olsson ML (2009) The ABO blood group system revisited: A review and update. Immunohematology 25: 4859.

13. World Medical Association (2013) World Medical Association Declaration of Helsinki: Ethical principles for medical research involving human subjects. JAMA 310: 2191-2194.

14. Sliwa K, Hilfiker-Kleiner D, Petrie MC, Mebazaa A, Pieske B, et al. (2010) Current state of knowledge on aetiology, diagnosis, management, and therapy of peripartum cardiomyopathy: A position statement from the Heart Failure Association of the European Society of Cardiology Working Group on peripartum cardiomyopathy. Eur J Heart Fail 12: 767-778.

15. Chobanian AV, Bakris GL, Black HR, Cushman WC, Green LA, et al. (2003) The seventh report of the Joint National Committee on Prevention, Detection, Evaluation, and Treatment of High Blood Pressure: The JNC 7 report. JAMA 289: 2560-2572.

16. Surawicz B, Childers R, Deal BJ, Gettes LS (2009) AHA/ ACCF/HRS recommendations for the standardization and interpretation of the electrocardiogram: Part III: Intraventricular conduction disturbances: A scientific statement from the American Heart Association Electrocardiography and Arrhythmias Committee, Council on Clinical Cardiology; the American College of Cardiology Foundation; and the Heart Rhythm Society: Endorsed by the International Society for Computerized Electrocardiology. Circulation 119: e235-e240. 
17. Lang RM, Badano LP, Mor-Avi V, Afilalo J, Armstrong A, et al. (2015) Recommendations for cardiac chamber quantification by echocardiography in adults: An Update from the American Society of Echocardiography and the European Association of Cardiovascular Imaging. European Heart Journal - Cardiovascular Imaging 16: 233-271.

18. Adeyemo OA, Soboyejo OB (2006) Frequency distribution of $\mathrm{ABO}, \mathrm{RH}$ blood groups and blood genotypes among the cell biology and genetics students of University of Lagos, Nigeria. African Journal of Biotechnology 5.

19. Egesie UG, Egesie OJ, Usar I, Johnbull TO (2008) Distribution of $A B O$, Rhesus blood and haemoglobin electrophoresis among the undergraduate students of Niger Delta State University, Nigeria. Niger J Physiol Sci 23: 5-8.

20. Jeremiah ZA (2006) Abnormal haemoglobin variants, ABO and Rh blood groups among student of African descent in Port Harcourt, Nigeria. Afr Health Sci 6: 177-181.

21. Sliwa K, Zhanje F, Candy G (2003) Peripartum cardiomyopathy: Clinicalprofile in 100 prospective patients studied at a single centre. Eur Heart J 24.

22. Twomley KM, Wells GL (2010) Peripartum cardiomyopathy: A current review. J Pregnancy 2010: 149127.

23. Ogunlade O, Akintomide AO (2013) Assessment of voltage criteria for left ventricular hypertrophy in adult hypertensives in south-western Nigeria. J Cardiovasc Dis Res 4: 44-46.

24. Musa A, Ndakotsu M, Abdul-Aziz H, Kilishi A, Aliyu I (2015) Distribution of $A B O$ and Rhesus blood group systems among blood donors in Sokoto North-western Nigeria. Journal of Applied Hematology 6: 136-138.

25. Jahanpour O, Pyuza JJ, Ntiyakunze EO, Mremi A, Shao ER (2017) $A B O$ and Rhesus blood group distribution and frequency among blood donors at Kilimanjaro Christian Medical Center, Moshi, Tanzania. BMC Res Notes 10: 738.

26. Adeyemo T, Ojewunmi O, Oyetunji A (2014) Evaluation of high performance liquid chromatography (HPLC) pattern and prevalence of beta-thalassaemia trait among sickle cell disease patients in Lagos, Nigeria. Pan Afr Med J 18: 71.

27. Carpeggiani $C$ (2011) The complexity of $A B O$ in coronary heart disease. The Lancet 377: 1492-1493.

28. Slade R, Alikhan R, Wise MP, Germain L, Stanworth S, et al. (2019) Impact of blood group on survival following critical illness: A single-centre retrospective observational study. BMJ Open Respir Res 6: e000426.

29. Kyari GV, Ayodele J (2014) The socio-economic effect of early marriage in North Western Nigeria. Mediterranean Journal of Social Sciences 5: 10.

30. Lee S, Cho GJ, Park GU, Kim LY, Lee T-S, et al. (2018) Incidence, risk factors, and clinical characteristics of peripartum cardiomyopathy in South Korea. Circ Heart Fail 11: e004134.

31. Karaye KM, Ishaq NA, Sa'idu H, Balarabe SA, Talle MA, et al. (2020) Incidence, clinical characteristics, and risk factors of peripartum cardiomyopathy in Nigeria: Results from the PEACE Registry. ESC Heart Fail 7: 235-243.

32. Bello N, Rendon ISH, Arany Z (2013) The relationship between pre-eclampsia and peripartum cardiomyopathy: $A$ systematic review and meta-analysis. J Am Coll Cardiol 62: 1715-1723.

33. Chima O, Mohammed T, Aisha K-G, Alhaji S, Muhammad $B$, et al. (2012) ABO and rhesus blood groups among blood donors in Kano, North-Western Nigeria. Nigerian Journal of Basic and Clinical Sciences 9: 11-13. 